\title{
Effect of Heat Break Geometry on the Thermal Performance of A 3D Printer Extruder
}

\author{
Ahmet Fatih Yuran (Corresponding author) \\ Afyon Kocatepe University, Faculty of Engineering, \\ Department of Biomedical Engineering, 03200, Afyonkarahisar, Turkey \\ E-mail: fatihyuran@aku.edu.tr \\ Ibrahim Yavuz \\ Afyon Kocatepe University, Faculty of Technology, \\ Department of Automotive Engineering, 03200, Afyonkarahisar, Turkey \\ E-mail: iyavuz@aku.edu.tr
}

The research is financed by Afyon Kocatepe University. 17. FEN. BIL. 75 (Sponsoring information)

\begin{abstract}
Fused Deposition Modeling (FDM) is one of the most frequently used additive manufacturing technologies due to its low cost. In FDM 3D printers, the production is carried out by melting the polymer filament extruder in the nozzle area. Extruder consists of two main structures: Hot - End and Cold - End. The temperature distribution in these two regions is the most important factor affecting the thermal performance of $3 \mathrm{D}$ printer. Heat Break is the region where heat transfer occurs between Hot End and Cold - End.

In this study, the effect of two different Heat Break geometries on thermal performance was investigated. One of the designs (HB0) consists of a standard diameter cylindrical geometry. In the second design (HB1), there is a narrowed section with a diameter of $2 \mathrm{~mm}$. Finite Element Method (FEM) was used to examine the thermal behavior of designs. Simulation results were verified with the images obtained with FLIR Lepton ${ }^{\circledR}$ Thermal camera. As a result, thermal camera images and thermal analysis results are consistent. Also, it was observed that the Heat Break design directly affected the general temperature distribution of the extruder. According to the results of the analysis, the minimum temperature in the heat break geometry with standard diameter cylindrical geometry was $86,512{ }^{\circ} \mathrm{C}$. In geometry with a narrowed cross section, the minimum temperature was $51,635^{\circ} \mathrm{C}$. The minimum temperature difference between the two geometries was measured as approximately $35^{\circ} \mathrm{C}$.
\end{abstract}

Keywords: Fused deposition modelling, Extruder, Thermal behaviour, Finite element method

DOI: $10.7176 /$ JSTR/6-12-05

\section{Introduction}

Subtractive manufacturing is a term for various controlled machining and material removal processes that start with solid blocks, bars, rods of plastic, metal, or other materials that are shaped by removing material through cutting, boring, drilling, and grinding. Additive manufacturing processes involve CAD softwares to design objects and build them by adding material layer by layer, while subtractive manufacturing removes material to create parts. The term "3D Printing" is increasingly used as a synonym for Additive Manufacturing [1]. The principle of adding layer by layer of the material allows us to produce a wide range of complex geometrical possibilities. For this reason, 3D printers are becoming more popular. 3D printers are used in industries such as medicine, aerospace and molding, automotive, dentistry, defense industry, architecture, personal equipment, jewelery [2]. 
3D printers use different techniques such as Stereolithography (SLA), Fused Deposition Modeling (FDM), Selective Laser Sintering (SLS), Selective Laser Melting (SLM), Electron Beam Melting (EBM) [3]. Among these techniques, FDM 3D printers have become widely used because of their low costs.

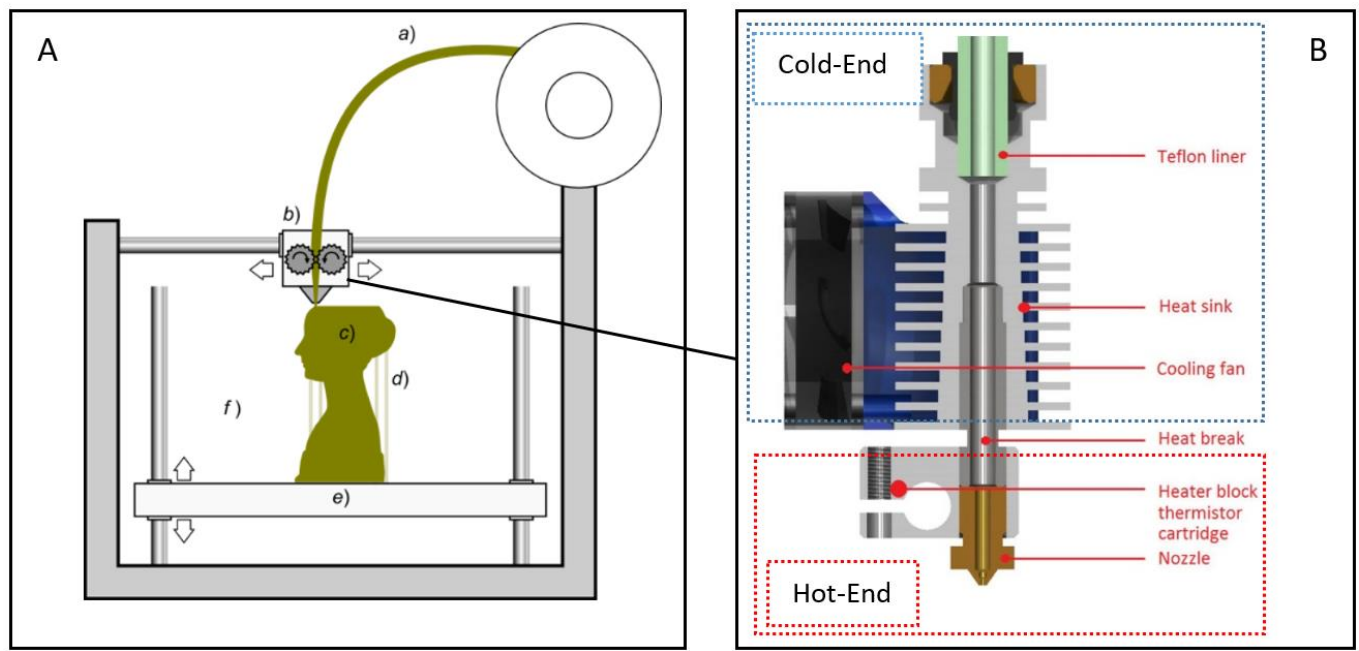

Figure 1. A. Schematic representation of the 3D printing technique known as Fused Filament Fabrication; a) filament b) extruder c) manufactured part d) support structures e) print bed. B. Detailed picture of the extruder [4].

Thermoplastics are mostly used as raw materials in order to produce functional prototypes in FDM 3D printers. Thermoplastics as PLA, ABS and Nylon can be made into wire in desired diameters and can be used as raw material in FDM printers. These materials in wire form are known as filaments. The filament (Fig 1a) is directed to the area called extruder (Fig 1b). When the nozzle reaches the desired temperature, the filament is melted in this region as a semi - liquid. Since the ambient temperature is much lower than the melting temperature of the semi - liquid filament, the material solidifies quickly after leaving the nozzle. The semi-liquid filament is extruded to the build plate (Fig 1e) according to the cross sections of the 3D digital model. In order to deposit the melted filament into the desired area, extruder system can move along the build table via motors. In addition, the build table can move horizontally in some 3D printers. After extruder complete the first layer of the part, the nozzle ascends a controlled height (layer height), and the next layer is deposited. When the production of all layers is completed, the part (Fig 1c) is manufactured.

Extruder is the most important part of a 3D printer. Extruder consists of two main structures: "Hot End" and "Cold - End" (Fig 1B). These two regions are thermally separated from each other. Filament must be kept as cold as possible to maintain its integrity at the Cold End. When the filament pass through heat break, nozzle temperature must be higher than glass transition temperature of the filament so that material can flow easily through the tip of nozzle. Heat transfer between the two structures must be prevented so that the filament can be properly feed along the Cold - End and only melted in the nozzle. If higher temperatures reach at the upper parts of the extruder, it will be difficult to feed the filament and it blocks the tip of the nozzle. In this case extruder will not be able to maintain continuous flow of melted filament. Thus, controlling the temperature distribution is primary challenge in extruder design. Optimal thermal behavior of the extrusion process can be defined as; Cold-End must be close to the room temperature $\left(20^{\circ} \mathrm{C}\right.$ ), while Hot - End must be steady at $220^{\circ} \mathrm{C}$, which is melting temperature of filament.

Previous studies showed that, various parameters affect extrusion quality such as infill parameters[5], printing speed[6] and printing direction[7,8]. Each parameter affects part quality, dimensional accuracy and strength. However, these studies mainly focus on production parameters, rather than explaining the thermal behavior of the extruder.

Yardimci et al. developed a mathematical model to predict the thermal behavior of extruder[9]. They proposed transient heat transfer models to explain the deposition process. Mesa et al. utilize 3D finite

42 | P a g e

www.iiste.org 
element simulations on temperature distribution on a commercial extruder at different cooling fan speeds[10]. Another study shows, if the amount of air delivered by a fan is increased, Cold - End can be kept at lower temperatures[11].

\section{Materials and Methods}

Two different heat break designs were modelled in SolidWorks CAD software. Thermal simulations were performed via ANSYS. In the experimental study, temperature distributions of both designs were examined by FLIR Lepton ${ }^{\circledR}$ Thermal camera and the simulation results were verified with these images.

\subsection{Extruder Designs and Material Properties}

Extruder has four main parts; Heat Sink, Heat Break, Heat Block and Nozzle. Heat Sink belongs to the Cold - End while Heat Block and Nozzle belong to Hot - End. Heat Break separates both parts. Heat Break acts as a separator between both parts. Heat Sink (Fig 2) placed on the upper part of the extruder and it has a finned structure. Also, a fan is usually connected to heat sink. In this way, a higher heat transfer is achieved with forced convection and the Cold - End zone can be kept at lower temperatures. It is made of aluminum to increase heat transfer rate (Table 1). Heat Block (Fig 2) is located in the Hot - End section and is made of aluminum in order to increase heat transfer. However, unlike Heat Sink, this piece is responsible for raising the temperature of the Hot - End region by transmitting heat better. The minimum temperature of this region should be at the glass transition temperature of the filament. A heating resistor and a thermistor are embedded inside Heat Block. Thermistor continuously measures the temperature.

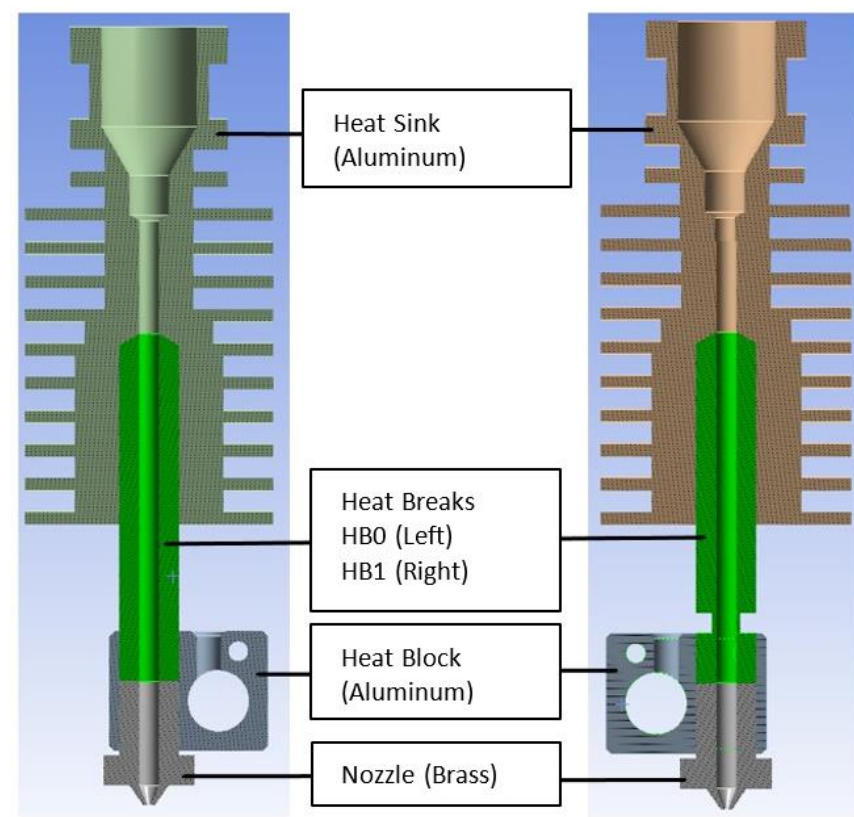

Figure 2. Two different extruder designs used in the study

Heating resistor keeps heating until the heat block reaches the desired temperature for example, $220{ }^{\circ} \mathrm{C}$, which is glass transition $\left(\mathrm{T}_{\mathrm{g}}\right)$ temperature for PLA. The heating resistor is turned off after the temperature exceeds $220^{\circ} \mathrm{C}$. If the heat block temperature drops below $\mathrm{T}_{\mathrm{g}}$ of the filament, the heating resistor is turned on again. Therefore, the heat block temperature fluctuates inevitably and it is often not possible to maintain a constant temperature. These fluctuations in temperature can affect filament melting process momentarily, but will not affect the overall temperature distribution of the extruder. Nozzle (Fig 2) is made of brass that is heated by heat block. Nozzle can be used in different diameters between $0.1 \mathrm{~mm}$ and $1 \mathrm{~mm}$. The nozzle diameter used in this study is $0.4 \mathrm{~mm}$. Heat Break (Fig 2) is responsible for isolating the heat between Hot - End and Cold - End. It is the second important part of the extruder that affects the temperature distribution after the heat sink. It is made of stainless steel, because of its lower thermal conductivity to reduce heat transfer (Table 1).

43 | $\mathrm{P}$ a g e

www.iiste.org 
Table 1. Thermal propeties of materials

\begin{tabular}{|c|c|c|}
\hline & Material & Thermal Conductivity $\left(\mathrm{W} \mathrm{m}^{\wedge}-1 \mathrm{C}^{\wedge}-1\right)$ \\
\hline Heat Sink & \multirow{2}{*}{ Aluminum Alloy } & $165\left(\right.$ at $\left.100{ }^{0} \mathrm{C}\right)$ \\
\hline Heat Block & & 175 (at $\left.200{ }^{\circ} \mathrm{C}\right)$ \\
\hline Heat Break & Stainless Steel & 15,1 \\
\hline Nozzle & Brass & 111 \\
\hline
\end{tabular}

\subsection{Heat Break Models}

Total length of the extruder used in the study is $75 \mathrm{~mm}$ and there is an aluminum Heat Sink which is 50 mm length with 10 fins (Fig 3). There is a $0.4 \mathrm{~mm}$ brass nozzle connected to a $12 \mathrm{~mm}$ thick Heat Block. Heat Block is heated with $12 \mathrm{~V} 40 \mathrm{~W}$ heating resistor and it is controlled by a thermistor. The main subject of the study is about heat break geometries. Two different Heat Break designs were examined. Except for heat breaks, other parts of the system were identical. The lengths of both heat break are $30 \mathrm{~mm}$ and threaded M6x1. One of the heat breaks has a $2 \mathrm{~mm}$ thinner section (HB1) in order to reduce heat transfer and the other heat break is flat (HB0) (Fig 3).

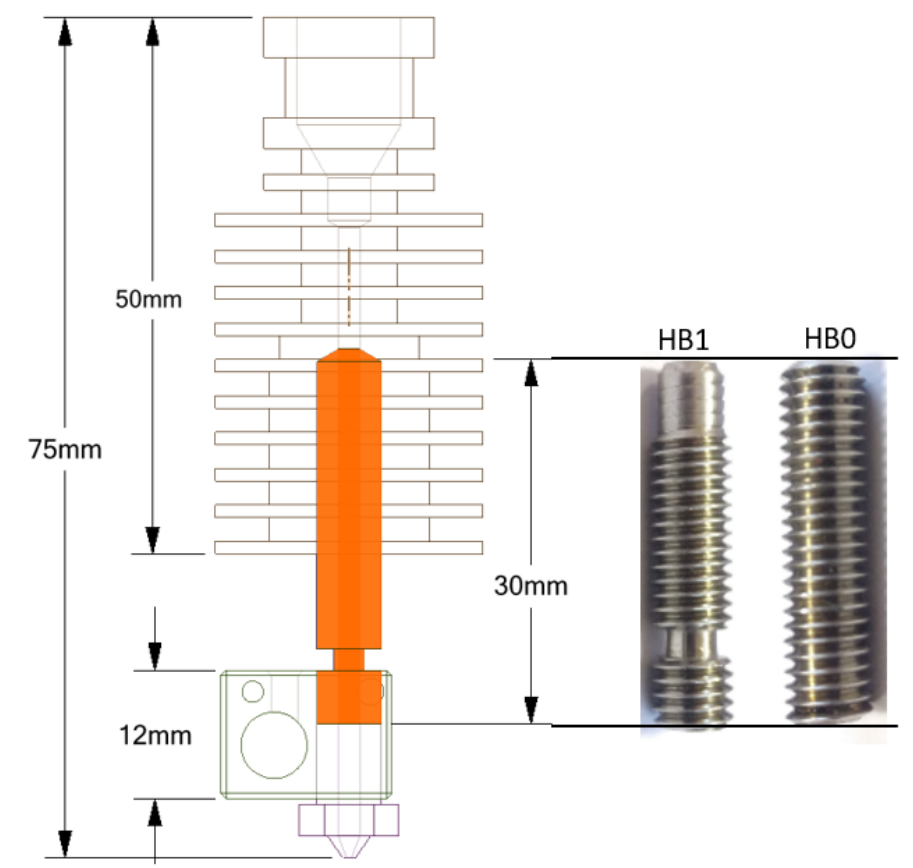

Figure 3. Extruder dimensions

\subsection{Finite Element Domain, Governing Equations and Boundary Conditions}

3D models of extruder designed in SolidWorks computer aided design program. ANSYS v19.2 software package is used to analyze the thermal distribution. It is assumed that there is no fan in the melting process to simplify the analysis. The analyzed domain is discretized using 10-Node Quadratic Tetrahedral Thermal Solid elements. The mesh of the system can be seen in Fig 4. Mesh of the HB1 model; consists of 1055691 elements and 1611211 nodes. HB0 model; includes 1656711 elements and 2393766 nodes. While creating the mesh, same element sizes were used in both models. 


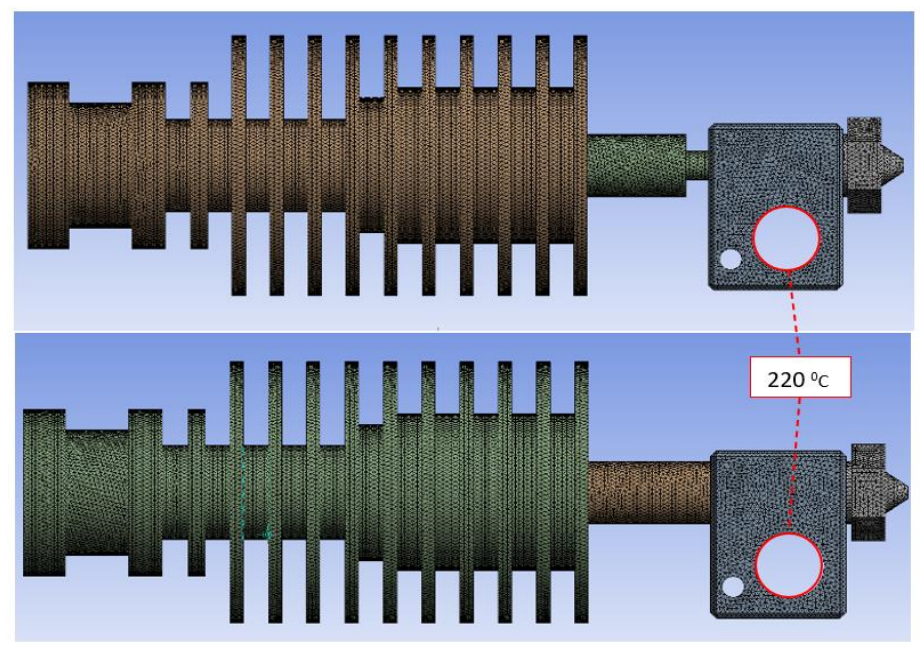

Figure 4. Mesh and boundary conditions

The analyzes are not time dependent. The system is assumed to be Steady - State. Extruder was initially considered to be at room temperature $\left(22{ }^{\circ} \mathrm{C}\right)$. Temperature, $220{ }^{\circ} \mathrm{C}$, boundary condition has been defined on the surface where the heating resistor is placed on the Heat Block (Fig 4.). Temperature fluctuations are not taken into account. It is assumed that the heat transfer between the parts takes place only by convection. Thermal conductivity of the parts in the system are given in the Table 1 . The temperature distribution on the extruder is $3 \mathrm{D}$ and can be obtained by solving differential equations of Fourier heat conduction law [12];

$$
\rho c \frac{\partial T}{\partial t}-\frac{\partial}{\partial x}\left(k \frac{\partial T}{\partial x}\right)-\frac{\partial}{\partial y}\left(k \frac{\partial T}{\partial y}\right)-\frac{\partial}{\partial z}\left(k \frac{\partial T}{\partial z}\right)+Q(x, y, z, t)=0
$$

Among the formula:

$\rho$ : shows the density of materials $\left(\mathrm{kg} / \mathrm{m}^{3}\right)$,

c: shows that the specific heat of materials $(\mathrm{J} /(\mathrm{kg} \cdot \mathrm{K}))$,

$\mathrm{k}$ : respectively show the heat transfer coefficient of material along the $\mathrm{X}, \mathrm{Y}, \mathrm{Z}$ direction $\left(\mathrm{W} /\left(\mathrm{m} 2 \cdot{ }^{0} \mathrm{C}\right)\right)$,

$\mathrm{T}$ : shows the temperature,

$\mathrm{t}$ : shows the time

$\mathrm{Q}=\mathrm{Q}(\mathrm{x}, \mathrm{y}, \mathrm{z}, \mathrm{t})$ : show the internal heat source density.

The heat balance equation shows that the incoming heat and the heat generated by the internal heat source are always in balance with the required heat for warming objects. Initial boundary condition at $\mathrm{T}_{0}$ is;

$$
\left.T(x, y, z, t)\right|_{t=0}=T_{0}
$$

No cooling fan was used to cool the extruder, so the system is cooled by natural convection;

$$
-\left.K \frac{\partial T}{\partial y}\right|_{y=0}=\varepsilon_{\theta} \sigma\left(T_{y=0}^{4}-T_{e n v}^{4}\right)+h\left(T_{y=0}-T_{\infty}\right)
$$

$\varepsilon_{\theta}$ : shows the effective emissivity of the object

$\sigma:$ shows Stefan - Boltzmann constant, $\left(\sigma=5.67 \times 10^{-8} \mathrm{~W} / \mathrm{m}^{2} \cdot \mathrm{K}^{4}\right)$

$\mathrm{T}_{\text {env }}$ : shows the environment temperature $(295 \mathrm{~K})$

$\mathrm{h}$ : shows convective heat transfer coefficient

45 | P a g e

www.iiste.org 
Heat fluxes can be observed to better understand the behaviour of Heat Break. The rate of heat transfer per unit area normal to the direction of heat transfer is called heat flux, and the average heat flux is expressed as;

where $\mathrm{A}$ is the heat transfer area.

$$
\dot{\mathrm{q}}=\dot{\mathrm{Q}} / \mathrm{A} \quad\left(\mathrm{W} / \mathrm{m}^{2}\right)
$$

\subsection{Thermal Camera}

Experimental studies were carried out under the same conditions for both models. Extruders are normally used with cooling fans. Thus, the transition of the temperature formed in the Hot - End region to the Cold - End section is reduced. However, in this study, since the effect of Heat Break geometry was investigated, no fan was used. Identical heater resistors are placed in both extruders. The resistor was heated to $220{ }^{\circ} \mathrm{C}$. The thermal images of the system were recorded with the FLIR Lepton ${ }^{\circledR}$ thermal camera. The thermal camera can record images with an accuracy of $\pm 4{ }^{\circ} \mathrm{C}$ in the range of $-20{ }^{\circ} \mathrm{C}$ $\pm 400{ }^{\circ} \mathrm{C}$. The properties of the thermal camera are given in Table 2 .

Table 2. Thermal camera parameters

\begin{tabular}{|l|l|}
\hline Characteristics & Parameters \\
\hline Effective Frame Rate & $8.7 \mathrm{~Hz}$ \\
\hline Pixel Size & $12 \mu \mathrm{m}$ \\
\hline Thermal Sensitivity & $<50 \mathrm{mK}\left(0.050^{\circ} \mathrm{C}\right)$ \\
\hline Optimum Temperature Range & $-10^{\circ} \mathrm{C}$ to $+80^{\circ} \mathrm{C}$ \\
\hline FOV - Diagonal & $71^{\circ}$ \\
\hline FOV - Horizontal & $57^{\circ}$ (nominal) \\
\hline
\end{tabular}

\section{Results}

\subsection{Thermal images}

When the thermal images are examined, the heater firstly raised the temperature of the heater block above $220^{\circ} \mathrm{C}$. After that the heat was spread through the Cold-End region of the extruder via Heat Break. In Figure 5a and 5b, thermal images of Heat Break with HB0 and HB1 show the heat distributions respectively. The HB1 model has a gap of $2 \mathrm{~mm}$ in size on Heat Break. When the thermal images are evaluated, it is seen that the gap reduces the heat transfer. HB1 model with gap has minimum temperature of $36,2{ }^{\circ} \mathrm{C}$, on the contrary $\mathrm{HB} 0$ model has $69,8{ }^{\circ} \mathrm{C}$. So, $2 \mathrm{~mm}$ gap made a $33.6^{\circ} \mathrm{C}$ contribution to the cooling of the system. In both models, the maximum temperatures are on the heater block. While the maximum temperature was $224,6{ }^{\circ} \mathrm{C}$ in model $\mathrm{HB} 0,225,6{ }^{\circ} \mathrm{C}$ was measured in HB1 model. 


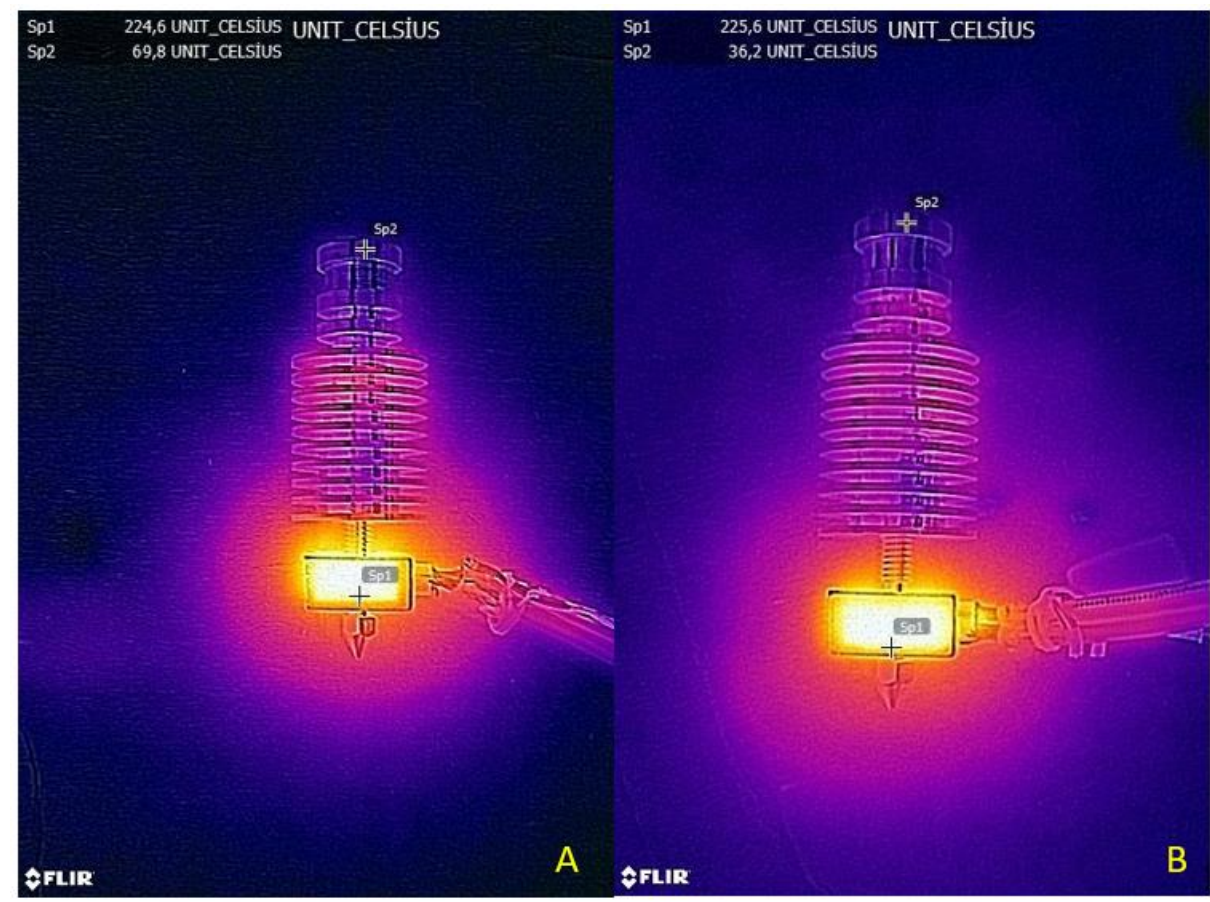

Figure 5. A. Thermal images of HB0 B. Thermal images of HB1

\subsection{Finite Element Analysis Results}

In thermal analysis, it is assumed that the system is steady state. Extruder was initially considered to be at room temperature $\left(22{ }^{\circ} \mathrm{C}\right) .220{ }^{\circ} \mathrm{C}$ temperature boundary condition has been defined on the surface where the heater is placed on the Heat Block. According to the results of thermal analysis, maximum and minimum temperatures were observed in the same regions for both heat break designs (Figure 6).

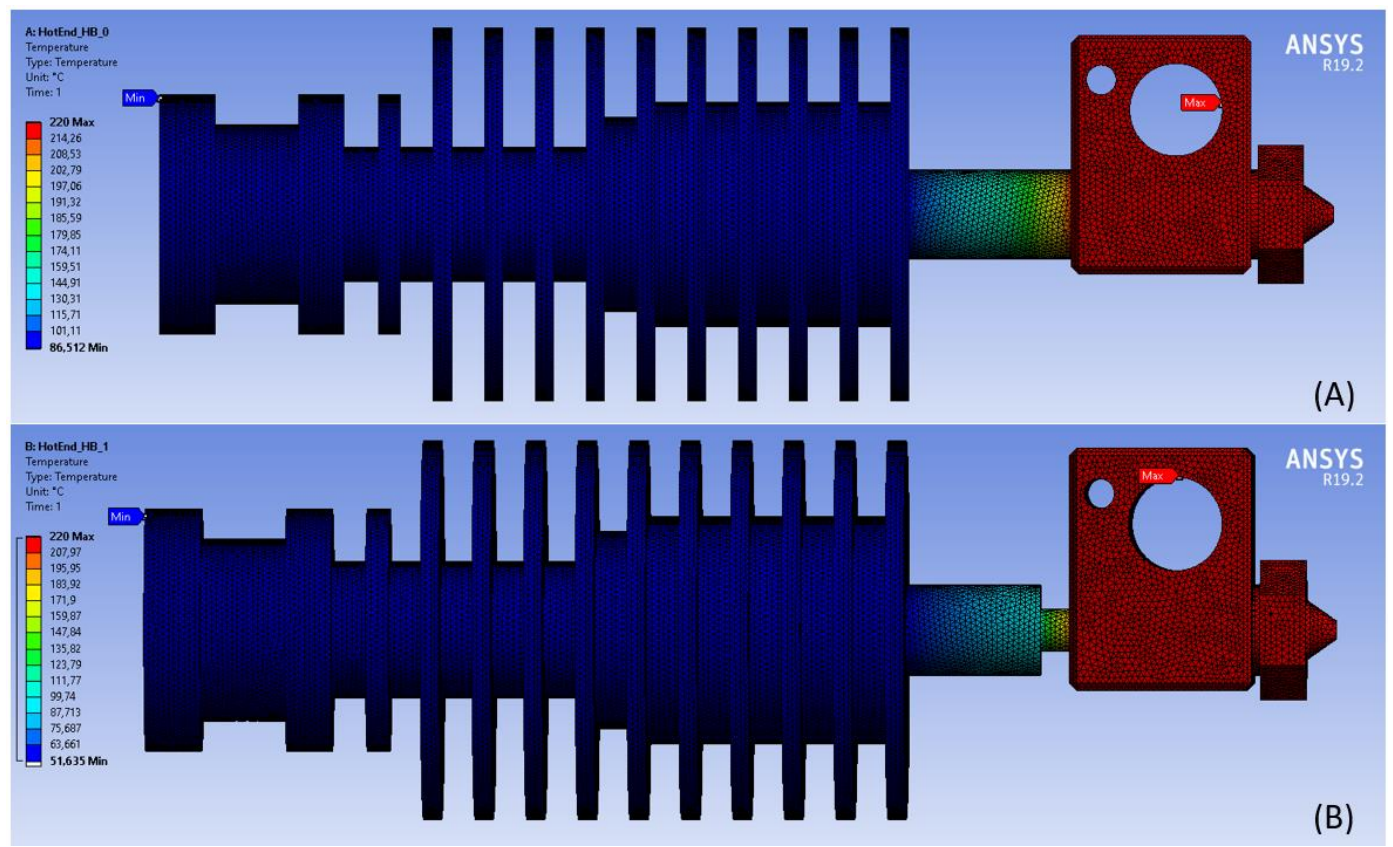

Figure 6. A. Temperature distribution of HB0 B. Temperature distribution of HB1 
When the minimum temperatures are evaluated, there is a small difference between the thermal camera images and the finite element analysis results. In thermal images of HB0 model, the minimum temperature was $69.8^{\circ} \mathrm{C}$, while in the simulation of the same model, the minimum temperature was obtained as $86.5^{\circ} \mathrm{C}$. In HB0 model, there is a difference of $16.7^{\circ} \mathrm{C}$ between experimental results and simulation results. Similarly, in the HB1 model, the minimum temperature in thermal images was $36.2^{\circ} \mathrm{C}$ while the minimum temperature was $51.6^{\circ} \mathrm{C}$ in the simulation of the same model and there is a $15.4{ }^{\circ} \mathrm{C}$ difference between experimental results and simulation results. This difference is related to thermal contact. Between solid objects in contact, heat flows from the hot body to the cold body. In heat transfer calculations, the contact surface between solid bodies is considered to be in perfect contact. However, in real life, a resistance occurs in the contact interface. Therefore, there are small differences between experimental results and simulations. However, considering the general temperature distributions of both models, the finite element analysis results coincide with the thermal images. When the minimum temperatures of both models are compared, the minimum temperature in the HB1 model is $34.87{ }^{\circ} \mathrm{C}$ lower than the HB0 model. This shows that the gap in the Heat Break geometry reduces the heat transfer. This is a desired result in terms of cooling the Cold - End. The rate of heat transfer per unit area normal to the direction of heat transfer is called heat flux. Heat fluxes for both models can be examined to compare different Heat Break geometries. Figure 7 shows the results of the heat fluxes on the HB0 and HB1 models. The simplest method to increase the heat flux is to increase the heat transfer surface. Contrarily, reducing the surface area reduces heat flux. In the HB0 model, the heat flux continues along the Heat Break surface. However, as can be seen in the HB1 model, the heat flux was lower compared to the other model due to the narrow cross-sectional area.

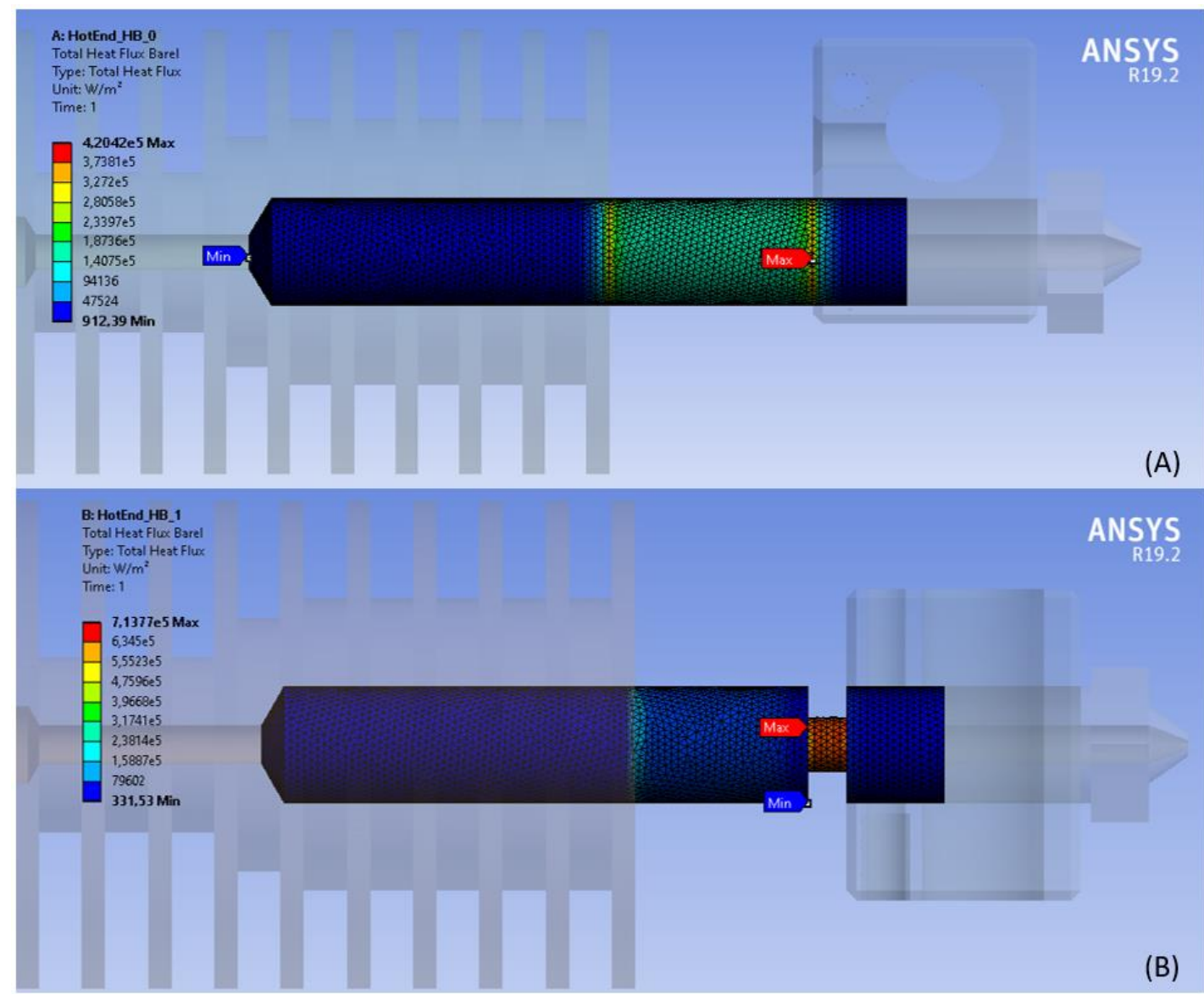

Figure 7. A. Heat flux in heat break of HB0 model B. Heat flux in heat break of HB1 model

The thermal properties of the parts used in the extruder directly affect the thermal behavior of the system. Brass $\left(\mathrm{h}_{\text {Brass }}=111 \mathrm{~W} / \mathrm{mC}^{0}\right)$ nozzles, which can be considered to have high thermal conductivity

48 | $P$ a g e

www.iiste.org 
coefficient, are used in order to transmit the heat formed in the Hot - End part to the filament faster. Similarly, aluminum $\left(\mathrm{h}_{\text {Aluminum }} \approx 165 \mathrm{~W} / \mathrm{mC}^{0}\right.$ ) materials are used to transfer the heat of Cold - End to environment and to cool it better. However, it should be ensured that heat transfer between Hot - End and Cold - End is as low as possible. Therefore; heat break, between these two structures, is supposed to be made of materials with lower heat transfer coefficient. The heat transfer coefficient of stainless steel $\left(\mathrm{h}_{\text {Steel }} \approx 15 \mathrm{~W} / \mathrm{mC}^{0}\right)$ is lower than other parts used in the extruder. So, stainless steel is a good material choice to use in heat break designs.

\section{Discussions}

An extruder consists of assembly of four parts which are nozzle, heat block, heat break and heat sink. Material properties of this components improve overall temperature distribution of extruder.

Brass nozzles with high thermal conductivity $\left(\mathrm{h}_{\text {Brass }}=111 \mathrm{~W} / \mathrm{mC}^{0}\right)$ are used to ensure that the temperature transfer to filament faster. Similarly, aluminum $\left(\mathrm{h}_{\text {Aluminum }} \approx 165 \mathrm{~W} / \mathrm{mC}^{0}\right)$ materials are preferred in heat sink to cool it better. However, heat transfer between Hot - End and Cold - End should be reduced as much as possible. Therefore; the heat break, between the Hot - End and Cold End, is made of stainless steel $\left(\mathrm{h}_{\text {Steel }} \approx 15 \mathrm{~W} / \mathrm{mC}^{0}\right)$ which has lower heat transfer coefficient.

Taking advantage of materials, thermal properties and cooling fan are the primary solutions in order to improve the thermal behavior of the extruder. However, the design and the geometries of the parts that used in the system is also effective on thermal behavior. The heat transfer between Hot - End and Cold - End especially takes place on the Heat Break. In this study, the effect of Heat Break design on the thermal behavior of the extruder was examined. The effect of two different Heat Break designs on the overall thermal distribution of the extruder investigated numerically by using the finite element method and the results of computer simulations were verified by thermal camera images.

In order to improve the thermal behavior of the extruder, the thermal conductivity of different materials, cooling elements and cooling fan are the first solutions. However, the designs of the parts forming the system are also effective on thermal behavior. Especially, heat transfer between Cold - End and Hot - End occurs on the Heat Break. Therefore, the Heat Break geometry strongly affects the thermal behavior of the extruder.

In this study, the effect of heat break design on thermal behavior has been demonstrated both experimentally and analytically. The results obtained from thermal analysis using the finite element method coincide with the results obtained from experimental studies. Further research, computer simulations can be used to evaluate different Heat Break geometries or different materials.

\section{References}

1. ASTM, I. "ASTM F2792-10: standard terminology for additive manufacturing technologies." ASTM International (2010).

2. Campbell, Thomas, et al. "Could 3D printing change the world." Technologies, Potential, and Implications of Additive Manufacturing, Atlantic Council, Washington, DC 3 (2011).

3. "Additive manufacturing - General Principles - Overview of process categories and feedstock". ISO/ASTM International Standard (17296-2:2015(E)). 2015.

4. Scopigno R., Cignoni P., Pietroni N., Callieri M., Dellepiane M. (2017). "Digital Fabrication Techniques for Cultural Heritage: A Survey". Computer Graphics Forum 36 (1): 6-21. DOI:10.1111/cgf.12781.

5. Afrose, M. F., Masood, S. H., Nikzad, M., \& Iovenitti, P. (2014). Effects of build orientations on tensile properties of PLA material processed by FDM. In Advanced Materials Research (Vol. 1044, pp. 31-34). Trans Tech Publications Ltd. 
6. Aw, Y. Y., Yeoh, C. K., Idris, M. A., Teh, P. L., Hamzah, K. A., \& Sazali, S. A. (2018). Effect of printing parameters on tensile, dynamic mechanical, and thermoelectric properties of FDM 3D printed CABS/ZnO composites. Materials, 11(4), 466.

7. Fernandez-Vicente, M., Calle, W., Ferrandiz, S., \& Conejero, A. (2016). Effect of infill parameters on tensile mechanical behavior in desktop $3 \mathrm{D}$ printing. $3 D$ printing and additive manufacturing, 3(3), 183-192.

8. Akhoundi, B., \& Behravesh, A. H. (2019). Effect of filling pattern on the tensile and flexural mechanical properties of FDM 3D printed products. Experimental Mechanics, 59(6), 883897.

9. Atif Yardimci, M., Hattori, T., Guceri, S. I., \& Danforth, S. C. (1997). Thermal analysis of fused deposition. In 1997 International Solid Freeform Fabrication Symposium.

10. Jerez-Mesa, R., Travieso-Rodriguez, J. A., Corbella, X., Busqué, R., \& Gómez-Gras, G. (2016). Finite element analysis of the thermal behavior of a RepRap 3D printer liquefier. Mechatronics, 36, 119-126.

11. Jerez-Mesa, R., Gomez-Gras, G., Travieso-Rodriguez, J. A., \& Garcia-Plana, V. (2018). A comparative study of the thermal behavior of three different $3 \mathrm{D}$ printer liquefiers. Mechatronics, 56, 297-305.

12. Cengel, Y. (2014). Heat and mass transfer: fundamentals and applications. McGraw-Hill Higher Education. 